\section{Civil power}

\section{to link with}

\section{weapons?}

\section{Washington}

The Reagan Administration has offered the US nuclear industry all of the moral and some of the economic - support that it wants. But even this may not be enough to restore the industry to health according to the parting words of the Nuclear Safety Oversight Commission (NSOC), an independent advisory body set up by President Carter following the Three Mile Island accident in March 1979.

Three main options face the Administration if it wants to save the civil nuclear industry, according to Governor Bruce Babbit of Arizona, chairman of NSOC. He presented President Reagan with this opinion when transmitting the commission's final report last month. Babbit warned, however, that each of the options would require a high political price.

The first option would be to regionalize the nuclear industry and draw it into the public power grids, a form of seminationalization already adopted, for example, by the Tennessee Valley Authority. The second would be to bail out the industry directly through government subsidies, although allowing it to remain largely in private hands.

The third and perhaps most controversial option would be to re-establish links between the commerical uses of nuclear power and the military demands for nuclear weapons, using the expansion of the latter to sustain the former. Some critics argue that the Administration's plan to use plutonium extracted from commercial wastes to provide fuel for weapons is already a step in this direction.

This drastic set of choices reflects the serious problems facing the industry. The most popular scapegoats have been the tough environmental regulations and stringent licence review procedures; but no less important has been the reduction in the rate of growth in power demand from 7 to 3 per cent a year over the past decade, and continued public concern about safety (highlighted by the design mistakes found in the Diablo Canyon reactor under construction in California).

The Administration has already taken several steps to assist the nuclear industry. In an attempt to encourage nuclear exports, for example, it is offering countries such as Mexico cut-price enriched uranium, and scientific collaboration in areas such as waste disposal and reactor safety.

Other measures are being taken to speed up the licensing of new plants. In a policy statement issued last month, Mr Reagan listed the goal of reducing the time needed to license and operate a new nuclear reactor from an average of 12 to 7 years as one of five steps intended to revitalize the nuclear industry (Nature 15 October, p.505).

Congress is likely to be sympathetic. Two weeks ago the House of Representatives passed a bill that would allow utility companies to start initial low-level operations of a new nuclear plant even before all local complaints had been fully heard. A similar measure, now before the Senate, is expected to pass with little difficulty.

The economic and safety problems facing the industry are unlikely to be resolved as simply. In the past few months several local utilities have decided to abandon plans for new reactors. In several cases, such as the Pilgrim II plant which was to have been built by Boston Edison Co. on the Massachusetts coast, construction delays and the need to incorporate new safety requirements have increased initial estimates of construction costs by about a factor of ten.

Many industry supporters feel that, in view of growing consumer opposition to the rapidly escalating electricity bills to

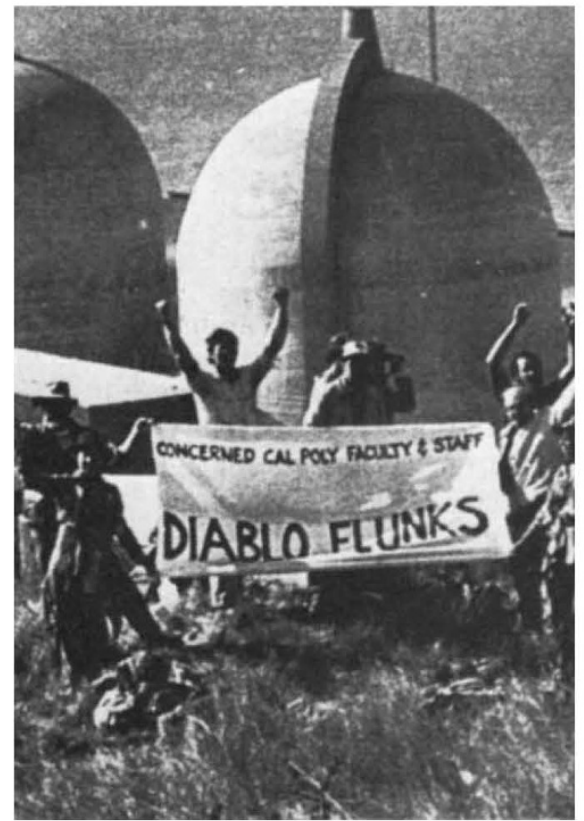

Waiting at Diablo Canyon

finance such construction - in some cases increasing by 500 per cent within a few years - the only way for the industry to remain viable is through a massive infusion of federal funds. But this possibility is already coming under fire from both sides

\title{
Irish veterinarians in dog-house
}

\section{Brussels}

A report by the European Commission on the eradication of cattle diseases has levelled an accusing finger at the Irish veterinary profession. Since 1965 about $£ 90$ million has been spent by the state on eradicating bovine tuberculosis in Ireland but, says the Commission, "there has been no change in the bovine tuberculosis situation in Ireland"'.

"It should not be concluded that this lack of progress is due to any lack of finance ( $£ 11$ million was spent in 1980) but rather to the fundamental fact that twothirds of the reactors are being missed at annual round testing" continues the report. The Commission does not accuse anyone of cheating. It does, however, draw a comparison with the results obtained during the early 1970 s by about 50 temporary veterinary inspectors employed by the Department of Agriculture to carry out tuberculin tests on a random sample of herds that were normally assigned to local veterinary surgeons for testing. The inspectors tested about 18 per cent of the national herd over several years and found approximately three times as many infected animals and herds as had the vets.

It would, of course, be to the farmers' advantage to avoid having their animals identified as being infected as this would involve high costs. Apart from the restrictions on the movement and sales of the animals and the need for proper handling and isolation facilities, the amount of compensation paid for slaughtered beasts does not match full market value, in contrast with the situation in the United Kingdom.

Faulty testing schemes may be the answer and the European Commission, which is proposing to continue with its accelerated programme to eradicate brucellosis, tuberculosis and leukosis in the $\mathrm{EEC}$, is threatening to cut off disease eradication funds to Ireland unless testing procedures are improved.

The EEC's contribution to the shared costs of accelerating the eradication of these diseases is some 130 million European Currency Units (about $£ 65$ million) over the past three years. The Commission confidently reports that by 1983 at the latest, all EEC herds will be under control as far as brucellosis and tuberculosis are concerned. By the end of the current programme, it is estimated that 1.5 million animals will have been destroyed.

Enzootic bovine leukosis will almost certainly be eradicated in Denmark in the near future and the disease is well under control in Germany. France and the United Kingdom have not availed themselves of EEC funds to eradicate leukosis. The Commission also studiously avoids contributing to the debate in the United Kingdom on the badgers and tuberculosis issue except to say that the disease has been practically eradicated there.

Jasper Becker 